\title{
Catalytic activity of metal acetate in transesterification of diphenyl carbonate and 1,4-butyldiol
}

\author{
Liping Wang ", Shuihua Zhang and Xiaolin Xu \\ College of Chemistry and Chemical Engineering, Qujing Normal University, P. R. China \\ wanglp_csu@163.com
}

\begin{abstract}
Keywords: Polycarbonate diols; Diphenyl caebonate; 1,4-Butyldiol; Metal acetate; transesterification Abstract. Synthesis of polycarbonate diols from diphenyl carbonate and 1,4-butyl diol has been demonstrated in the presence of metal acetate catalysts. Alkali metal acetate and alkaline earth metal acetate catalysts showed much higher catalytic activity, of them, lithium acetate was the most active. And the catalytic mechanism was discussed.
\end{abstract}

\section{Introduction}

Aliphatic polycarbonate diols (PCDL) is a polymer whose terminal group is hydroxyl group, main chain containing sub-alkyl and carbonate-based repeating unit. It is widely used in synthetic leather, TPU, SPANDEX, adhesives, paint and other areas [1]. Its important downstream product of polyurethane material with excellent performance and a wide variety of characteristics, is widely used in construction, chemical industry, light industry, mechanical and electrical, metallurgical, medical and health and other fields. Its demand for an annual growth rate is $6 \% \sim 8 \%$, the global consumption of polyurethane materials has reached more than 11 million tons in 2006, forming a large category of synthetic materials, and has been ranked No. 6 of synthetic materials [2]. Polyurethane produced from PCDL is superior to the ones from polyether diol or polyster diol in mechanical performance, heat resistance, oil resistance, hydrolytic resistance, oxidizing resistance, abrasion resistance, chemical resistance and weather resistance. PCDL performs excellently with respect to hydrolytic resistance and aging resistance, its outstanding properties enables it be used extensively in each area of polyurethane [3]. Therefore, PCDL is a broad development prospect of the chemical.

PCDL can be prepared by various methods: the reaction of phosgene with diol[4], the copolymerization of oxiranes with $\mathrm{CO}_{2}$ [5], the polymerization of six- and seven-membered cyclic carbonates[6] and the transesterification of carbonate with diol[7-9]. As a result of using highly toxic phosgene and large numbers of byproducts hydrogen chloride causing serious corrosion of equipment, the method of phosgene reaction with diol has been basically eliminated. $\mathrm{CO}_{2}$ is the most abundant and cheap resources of $\mathrm{C}_{1}$. But PCDL with specific epoxide structure is only synthesized. The cost of synthesis of cyclic carbonate is much higher, so the polymerization of six- and seven-membered cyclic carbonates is of little value for industrial application. Compared with other methods, the advantages of the transesterification include greater flexibility for the synthesis of all possible structures and controlled programming of the molecular weight of the target products [12].Carbonate used in the transesterification includes dimethyl carbonate (DMC) [7-8], diethyl carbonate (DEC)[9] and diphenyl carbonate (DPC)[10]. Due to lower boiling point and forming azeotrope with side product methanol, $\mathrm{DMC}$ is easy to be removed from the reactor. DEC is unable to form azeotrope with byproduct ethanol, and ethanol is non-toxic. But DEC can tract into the body through gastrointestinal tract, skin and respiratory for the middle-performance for toxicity. Besides, DEC is easy to form an explosive mixture with air. In constant, DPC is not only environmentally friendly compound but has higher boiling point. Though the side product phenol is toxic, but it can be recycled to synthesize DPC by ester interchange with DMC. So the transesterification of DPC and aliphatic diol is a more promising route to prepare PCDL.

The transesterfication of DPC with 1,4-butyl diol (BD) can proceed without catalyst, but the reaction is quite slow. So use of catalyst is necessary in this reaction. There are a few catalysts used in transterfication of DMC or DEC and diol [7-9]. But few catalysts reported are used to catalyze DPC 
reaction with BD. Metal acetate catalysts are active catalysts for ester exchange reaction [12-13]. In this work, the activities of various metal acetate catalysts were evaluated, and the catalytic mechanism was discussed.

\section{Experimental}

The reaction was carried out in a $100 \mathrm{~mL}$ round-bottomed flask equipped with thermometer, a nitrogen inlet, a mechanical stirrer and reflux condenser. DPC, BD and the catalyst were introduced into the flask under nitrogen atmosphere. The reaction temperature was kept between 186 and $196^{\circ} \mathrm{C}$. The temperature of distillation column was maintained at $180^{\circ} \mathrm{C}$. The byproduct phenol was collected in a flask.

Qualitative and quantitative analyses of distillate were carried out a Shimadzu GC-2010 gas chromatograph equipped with a flame-ionization detector. The yield of phenol was expressed in percent of its theoretical value, which was calculated based on the $100 \%$ conversion of DPC. The reaction residue was a yellow solid, after cooling, then it was dissolved in dichloromethane and precipitated by addition of ethyl alcohol. IR spectra of the product obtained were recorded on a Nicolet 460 Fourier transform infrared spectroscopy. ${ }^{1} \mathrm{H}$ NMR and ${ }^{13} \mathrm{C}$ NMR spectra were recorded on a Bruker Avance III $500 \mathrm{MHz}$ spectrometer.

The IR spectra of PCDL: the band at $3454.8 \mathrm{~cm}^{-1}$ is the absorption of $-\mathrm{OH}$, the bands at $2965.8 \mathrm{~cm}^{-1}$, $2936.3 \mathrm{~cm}^{-1}, 2873 \mathrm{~cm}_{1}, 1459.0 \mathrm{~cm}^{-1}$ and $1403.6 \mathrm{~cm}^{-1}$ are the characteristic absorption of $\mathrm{CH}_{2}$, the band at $1732 \mathrm{~cm}^{-1}$ is the absorption of carbonate $\mathrm{C}=\mathrm{O}$, the bands at $1269 \mathrm{~cm}^{-1}$ and $1246.2 \mathrm{~cm}^{-1}$ are the absorption of aliphatic carbonate $\mathrm{O}-\mathrm{C}-\mathrm{O}$ (see Fig1).

1H NMR $\left(\mathrm{CDCl}_{3}\right): \delta=4.17\left(\mathrm{t}, \mathrm{OC}(\mathrm{O}) \mathrm{OCH}_{2}\right), \delta=3.66\left(\mathrm{t}, \mathrm{HOCH}_{2}\right), \delta=1.63\left(\mathrm{t}, \mathrm{OC}(\mathrm{O}) \mathrm{OCH}_{2} \mathrm{CH}_{2}\right)$, $\delta=1.55\left(\mathrm{t}, \mathrm{HOCH}_{2} \mathrm{CH}_{2}\right)$.

$13 \mathrm{C} \quad \mathrm{NMR} \quad\left(\mathrm{CDCl}_{3}\right): \delta=155.20 \quad(\mathrm{C}=\mathrm{O}), \quad \delta=67.8 \quad\left(\mathrm{C}(\mathrm{O}) \mathrm{OCH}_{2}\right), \quad \delta=62.3 \quad\left(\mathrm{HOCH}_{2}\right), \quad \delta=25.2$ $\left(\mathrm{C}(\mathrm{O}) \mathrm{OCH}_{2} \mathrm{CH} 2\right), \delta=28.9\left(\mathrm{OHCH}_{2} \mathrm{CH}_{2}\right)$.

The progress of the reaction was followed by measuring the yield of phenol expressed in percent of its theoretical value which was calculated based on the $100 \%$ conversion of DPC. As shown in Table 1 , alkali metal acetate and alkaline earth metal acetate catalysts showed much higher catalytic activity. The order of the activity of alkali metal acetate is lithium acetate $>$ sodium salt $>$ potassium acetate. The order of the activity of alkaline earth metal acetate is magnesium acetate $>$ calcium acetate $>$ barium acetate. Of them, lithium acetate is the most active.

Table 1 Yield of phenol formed with various metal acetates as catalysts

\begin{tabular}{llc}
\hline No & Catalyst Name & Yield of Phenol (\%) \\
\hline 1 & None & 4.6 \\
2 & Lithlum acetate & 70.5 \\
3 & Sodium acetate anhydrous & 66.2 \\
4 & Potassium acetate & 59.6 \\
5 & Magnesium acetate & 50.3 \\
6 & Calcium acetate & 44.4 \\
7 & Barium acetate & 38.6 \\
8 & Lead acetate & 32.2 \\
9 & Manganese acetate & 24.1 \\
10 & Cobaltous acetate & 24.3 \\
11 & Cupric acetate & 31.7 \\
12 & Zinc acetate & 35.6 \\
\hline
\end{tabular}

Reaction temperature: $196{ }^{\circ} \mathrm{C}$, molar ratio of BD and DPC: 1.2 , the mole ratio of catalyst to DPC: 0.002, reaction time: $4 \mathrm{~h}$, the mole of DPC: $0.23 \mathrm{~mol}$

Oxygen is more electronegative than carbon, and thus pulls electron density away from carbon. So the carbonyl group is polar, the partial positive charge on carbonyl carbon causes it be attacked by 
nucleophiles, the partial negative change on carbonyl oxygen causes it be attacked by electrophiles. And the carbonyl carbon with positive charge has a greater reactivity than carbonyl oxygen with negative charge. The transesterification may proceed by the nucleophilic attack of hydroxyl group in BD upon carbonyl group in DPC. The phenoxy group is an electron-donating group, it can increase negative charge of carbonyl carbon and thus reduce electrophilic capacity of carbonyl carbon, and it increases steric hindrance and thus makes it difficult for carbonyl carbon to close with nucleophiles.

In presence of metal acetate, the reaction intermediate is considered as a complex formed by coordination of the carbonyl group to the metal species. This coordination increases the positive charge of carbonyl carbon and facilitates the nucleophilic attack of hydroxyl group upon this positively polarized carbon atom (Scheme 1). In conclusion, all of metal acetate catalysts tested had catalytic activity to the reaction of DPC with BD. Among them, alkali metal acetate and alkaline earth metal acetate catalysts had much higher activity, and lithlum acetate was the most active. The small quantity of crystal water in the catalysts could not affect the reaction, so the catalyst can be directly used without any pretreatment. And metal acetate catalysts are commercial available and inexpensive. As a promising road for preparation of PCDL, the further study on this reaction is underway in our lab.
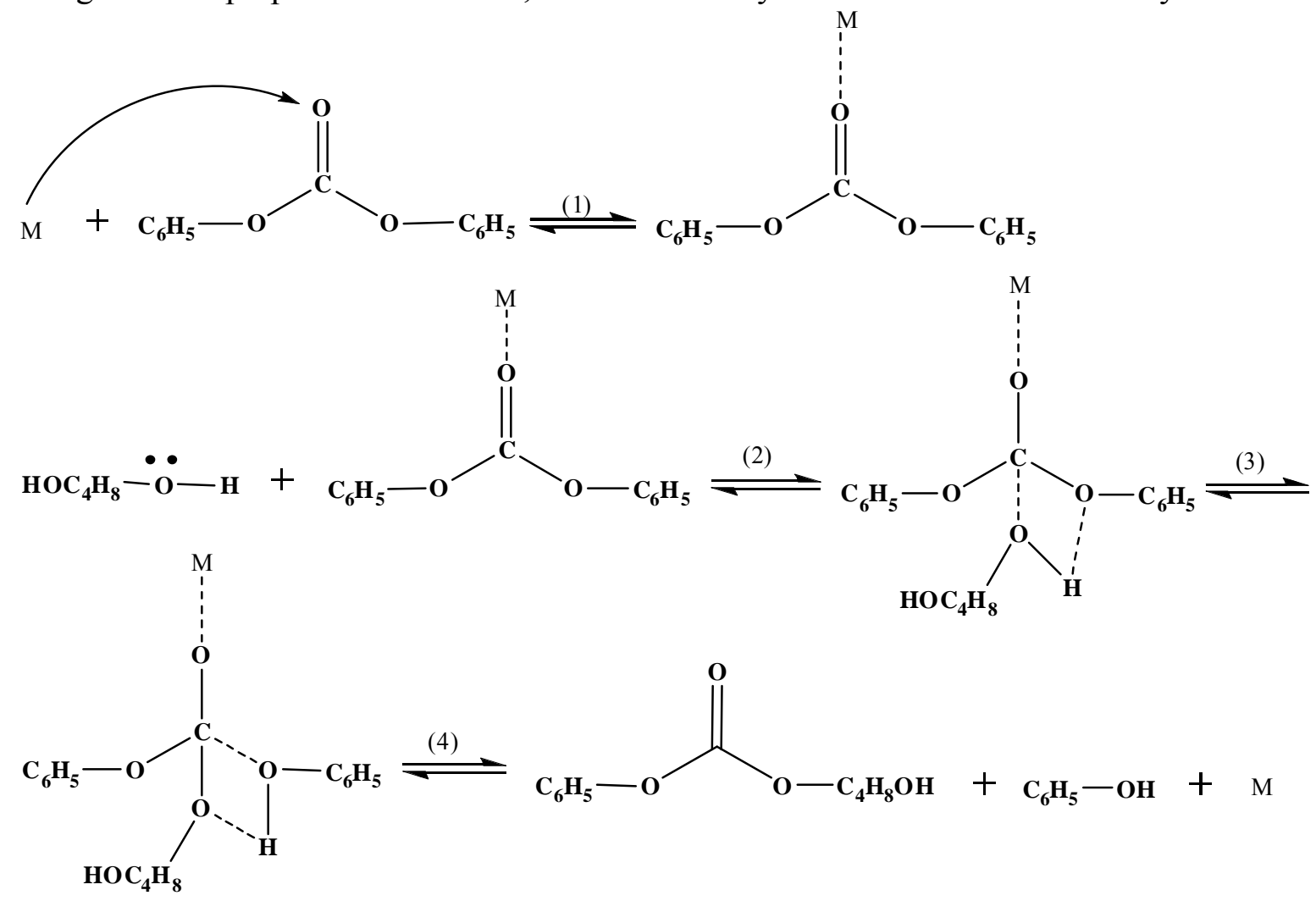

Scheme 1 Possible reacton mechanism

\section{Conclusions}

Lithlum acetate shows has exhibits higher catalytic activity for the synthesis of PCDL via the transesterification between DPC and BD. And the crystal water in the lithlum acetate could not affect the reaction, so lithlum acetate catalyst can be directly used without any pretreatment.

\section{Acknowledgements}

This work was supported by Yunnan Provincial Applied Basic Research Program (2013FZ108), China.

\section{References}

[1] B.Y. Ding, Y.H. Pan, H.Y. Wang, Coatings Technology \& Abstracts. 27(2006)11-14. 
[2] Y.X. Ou, X.J. Wang (Eds), Polyurethane and Analysis of Its Raw Material, Weapon Industry Press, Beijing, 1991, pp, 26-28.

[3] D.K. Lee, H.B. Tai, H.H. Wang, R.S. Tsai, Journal of Applied Polymer Science. 94(2004)1723-1729.

[4] H. Schnell, Chemistry and Pysics of Polycarbonates, Wiley, New York, 1964, pp, 9.

[5] M. Stephen, P. Timothyl, R.Andrzej,U.S. Patent 5,026,676 (1991).

[6] H. Hocker, H. Heul, Cyclic carbonates (ring-opening polymerization). C.Salomonel (Ed), Polymeric materials encyclopedia, Boca Raton, FL, CRC Press, 1996, pp, 1647.

[7] Y.X. Feng, N. Yin, F.Q. Li, J.W. Wang, M.Q. Kang, X.K. Wang, Industrial \& Engineering Chemistry Research. 47(2008)2140-2145.

[8] S. Hofacker, R. Bachmann, H. Witossek, U.S. Patent, 0,055,360 (2005).

[9] V.B. Pokharkar, S. Sivaram, Journal of Controlled Release, 41(1996)157-162

[10] S. Hofacker, C.Gurtler, J.Tillack, U.S. Patent 0,125,176 (2003).

[11] G. Alberto, US 5847069 (1998).

[12] D. Zhang, Sh.Y. Jia, Y. Wang, J. Yao, G.Y. Wang, Chemical Research In Chinese Universities, 23(2007)172-175.

[13] M.D. Serio, R. Tesser, F. Trulli, Journal of applied polymer science, 62(1996)407-415. 